\title{
RANCANG BANGUN APLIKASI PEMESANAN MENU KULINER BERBASIS ANDROID
}

\author{
Reni Haerani ${ }^{1}$, Haviza ${ }^{2}$ \\ ${ }^{1,2}$ Program Studi Manajemen Informatika Politeknik PGRI Banten \\ Jl.Raya Cilegon - Serang KM.12 Serdang Kramatwatu Serang - Banten 42161 \\ ${ }^{1}$ renihaerani@politeknikpgribanten.ac.id, \\ ${ }^{2}$ havizapijah@gmail.com
}

\begin{abstract}
Abstrak
Restoran Warung Cilegon Banten atau Warciban adalah bisnis yang bergulir pada bidang masakan dan sudah dikunjungi oleh masyarakat khususnya para remaja. Berlokasi di kota Cilegon - Banten yakni sejenis bisnis usaha didunia masakan yang menyuguhkan beragam hidangan kuliner dan minuman. Penelitian ini menggunakan teknik Rapid Application Development (RAD). Metode RAD memungkinkan mekanisme bentuk pembangunan aplikasi yang ringkas. Tujuan penelitian yang ingin digapai antaral ain adalah mempermudah dan meningkatkan dalam kecepatan pada proses pemesanan kuliner dan minuman akibatnya mengurangi kesalahan ketika pendataan, mengurangi ketidakpuasan yang diakibatkan oleh kesalahan pelayan terhadap pelanggan dan meningkatkan kecepatan proses pelayanan pemesanan hidangan kuliner dan minuman serta memudahkan owner menerima rekap data output penjualan. Selama ini Warciban dalam melakukan proses pelayanan pemesanan masih secara manual, dan masih memakai pencatatan yang belum terkomputerisasi. Dimana konsumen wajib menanti relatif lama buat pesanan kuliner dan minuman, selain itu pula pramuniaga mengalami kesulitan dalam mencatatkan order dengan menggunakan kertas. Proses transaksi order secara manual kurang efisien memerlukan waktu yang lama. Sehingga buat memperhatikan kepuasan pelanggan pada proses pesanan dibuatlah aplikasi pemesanan kuliner dan minuman berbasis android dengan menggunakan PHP dan MySQL yang sanggup digunakan pihak Warciban kapan dan dimanapun secara cepat dan tepat.
\end{abstract}

Kata kunci: Sistem Informasi, Pemesanan Kuliner dan Minuman, Rapid Application Development, Android

\section{PENDAHULUAN}

Kecepatan kemajuan teknologi informasi era ini, membawa manusia masuk di dalam aktivitas yang beriringan dengan informasi dan teknologi. Pada era digital informasi saat ini, masih banyak peranti komputer berikut aplikasinya yang mendukung dan memudahkan aktivitas di pelbagai bidang, termasuk komputer yang dikemas berbentuk mobile sehingga ringan untuk dijinjing, serupa tablet, Smartphone. Banyaknya aplikasi berbasis komputer yang diimplementasikan di perusahaan atau organisasi membuat pola kerja menjadi berubah dari tradisional menjadi digital. Masyarakat telah banyak mengenal smartphone dengan platform berbasis Android, penentuan Android untuk peningkatan aplikasi sebab lebih gampang dalam operasionalisasi serta juga sangat adaptif. Masyarakat telah menggunakan aplikasi berbasis Android di pelbagai sektor, baik dalam dunia pendidikan, hiburan serta bidang bisnis spesifik di bidang kuliner diantaranya restoran dan kafe [1].

Restoran Warung Cilegon Banten atau Warciban yakni usaha yang bergulir di bidang kuliner dan sudah dikunjungi oleh masyarakat terutama para remaja. Berlokasi di kota Cilegon Banten yang menyajikan beraneka jenis menu makanan dan minuman. Semasa ini Warciban didalam mengerjakan proses pelayanannya masih cara manual, dimana pramuniaga mendatangi konsumen dan mencatatkan order pada kertas yang akan diberikan ke bagian kitchen dan kasir. Dalam menghadapi persaingan bisnis saat ini, sistem manual tersebut tidak dapat lagi diterapkan dan kurang efektif dan kemungkinan terjadi kekeliruan penulisan yang mengakibatkan orderan tidak cocok serta terdapat pesanan yang rangkap. Minimnya pemahaman dalam membagikan berita secara real time, berdampak informasi yang disampaikan tidak mutakhir, sehingga di setiap kondisi informasi yang disampaikan sudah kadaluarsa [2]. Selain 
daripada itu, proses orderan dengan manual kerap terjadi kesalahan dalam antrean order, hal demikian berefek negatif pada kepuasan pelanggan. Oleh karena itu, dibutuhkan aplikasi untuk memanage semua menu pesanan sesuai yang dibutuhkan customer, serta yang dibutuhkan bagian restoran tersebut [3]. Membuat satu aplikasi pesanan menu berbasis Android yang bisa mendukung prosedur servis seperti mengelola antrian order sesuai waktu pesanan customer, mengontrol kapasitas kesiapan menu secara real-time, dan bisa mengontrol banyaknya orderan [4] maupun rekapitulasi data untuk report transaksi yang digunakan pada restoran Warciban.

Metode Penelitian menggunakan Rapid Application Development (RAD). Desain RAD membolehkan operasi model pembangunan software yang ringkas. Model RAD merupakan sebuah adaptasi kecanggihan dari model waterfall. Kegiatan RAD mengharuskan developer untuk mendesain suatu sistem informasi yang berperan penuh [5]. Studi kasus sebelumnya menggunakan metode pengembangan sistem adalah metode waterfall dengan menggunakan perangkat modem GSM berupa chip kartu dimana customer bisa pesan menu hidangan dengan cara mengetik kata kunci yang sudah ditetapkan dan user bisa berkomunikasi dengan aplikasi pesanan makanan secara online. SMS order menu makanan yang diterima dari customer akan dikerjakan aplikasi dengan mentransfer list menu dan order customer berdasar kode menu yang sudah disetting dan jika orderan tersaji maka akan dikirim oleh rumah makan ke tempat tujuan [6].

Tujuan penelitian yang hendak dicapai diantaranya adalah memudahkan dan memperlancar proses pesanan makanan dan minuman sehingga mengurangi kesalahan pada saat pendataan, mengurangi ketidakpuasan efek kesalahan pelayan terhadap customer dan menyegerakan proses pelayanan pesanan menu kuliner dan minuman serta memudahkan owner mendapatkan rekap data hasil penjualan. Penelitian ini menghasilkan sebuah aplikasi yang dapat membuat pesanan makanan dan minuman yang dapat digunakan pihak Warciban secara cepat, efektif dan efisien. [7].

\section{A. Rapid Application Development (RAD)}

Rapid Application Development atau rapid prototyping adalah bentuk metode membangun software yang tercantum dalam teknik bertingkat . Rapid Application Development memfokuskan pada daur pembentukan secara ringkas dan tepat. Untuk mendevelop suatu aplikasi secara normal dibutuhkan durasi minimum enam bulan, akan tetapi dengan memakai proses RAD suatu sistem informasi bisa dikerjakan kurun waktu 30-90 hari. RAD memakai cara iterative (berulang) dalam pengembangan sistemnya, working model sistem dibangun di awal tahap ekspansi bertujuan memastikan user requirement. Cara kerja dipakai hanya sewaktu-waktu saja sebagai dasar rancangan dan penerapan sistem akhir [10]. Teknik RAD adalah pendekatan berorientasi objek dalam mewujudkan suatu sistem dengan target utama mempercepat durasi penggarapan aplikasi. Prosedur ini menitikberatkan kesertaan user dalam melakukan analisa dan perancangan, dengan begitu kebutuhan pengguna dapat terpenuhi secara baik dan transparan serta menumbuhkan tingkat kepuasan pengguna sistem informasi [7]. Model RAD memiliki 3 tahap, berikut deskripsinya :

\section{Requirement Planning}

User dan analyst melaksanakan diskusi untuk menandai objek dan keperluan dari sistem informasi agar target tercapai. Tahapan ini merupakan hal sangat penting yakni adanya keterkaitan dari dua belah pihak diantara satu dengan yang lainnya.

2. Proses Design System dan Testing Pada tahapan ini aktivitas user yang terlibat memastikan mempercepat target dikarenakan proses ini melaksanakan reparasi jika masih ada ketidaksesuaian desain antara pengguna dan data analyst. Tahapan pengujian dalam sistem dan menilai apakah aplikasi bisa bekerja sinkron dengan fungsionalitas yang diharapkan.

3. Implementation

Tahap ini adalah fase programmer menguraikan rancangan suatu agenda yang sudah disetujui oleh user dan analyst

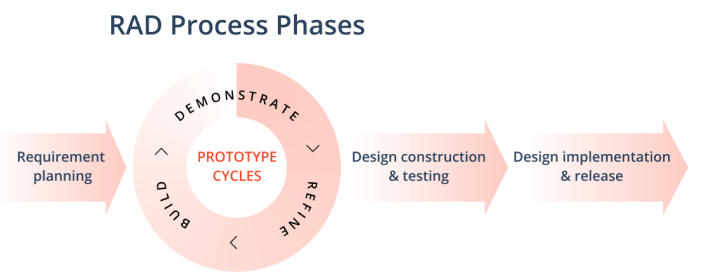

Gambar 1. Model Rapid Application Development (RAD)

\section{B. Android}

Merupakan Operating System (OS) mobile yang muncul ditengah perkembangan OS lainnya dewasa ini. Berdasarkan buku (Jubilee Enterprise, 2015), Android adalah sistem operasi untuk smartphone berbasis Linux yang dipersiapkan buat gawai seluler touchscreen semacam telepon pintar dan komputer tablet. Namun, OS saat ini beroperasi dengan prioritas rekayasa inti yang dikembangkan 
mandiri tanpa memperhatikan kapasitas dari aplikasi pihak ketiga yang cukup besar [11]. Oleh sebab itu, ada keterikatan untuk memperoleh data asli ponsel, berkomunikasi antar proses serta adanya keterbatasan distribusi pada platform aplikasi pihak ketiga [12].

\section{Web Service}

Komputasi yang bisa dicapai melewati jejaring internet dan intranet menggunakan platform protokol standar dengan interface bahasa pemrograman yang independen [13]. Web Service selalu tersambung ke internet. Setiap Web Service yang tersambung ke internet akan dilengkapi dengan address khusus yang dilapis dengan deretan empat nomor antara 0 dan 255 yang dibedakan oleh periode. Selain dari itu, Web Service membolehkan fasilitator hosting mengatur beberapa domain (pengguna)di server tunggal [14].

\section{Web Application Programming Interface (API)}

Application Programming Interface membolehkan pengembang mengintegrasikan dua unsur aplikasi atau yang berbeda secara berbarengan. API berisi dari beragam elemen seperti function, protocols, dan tools yang mengharuskan developers untuk membangun aplikasi. Penerapan API bertujuan agar memperlancar proses development dengan cara menyimpan function secara terpisah sehingga pengembang tidak harus mewujudkan fitur yang sejenis. Implementasi API akan sangat dirasa bila fitur yang diharapkan sudah benar-benar kompleks, pastinya membutuhkan durasi untuk membuat yang serupa. Semisal: integrasi payment gateway. Ditemukan berbagai bentuk sistem API yang bisa digunakan, termasuk sistem operasi, library, dan web [15].

Pada penelitian ini berfokus dalam penggunaan metode RAD untuk sistem pesanan makanan dan minuman berbasis android mengetahui Penelitian terdahulu sistem pesanan makanan dan minuman yang juga membahas mengenai metode RAD menggunakan mobile android dibahas pada penelitian [16] [9]. Perbedaan dari penelitian sebelumnya, penelitian ini dirancang memudahkan pemesanan menu secara real time dan rekap data untuk laporan transaksi. Harapan dengan adanya sistem informasi ini mampu mengatur dan mempermudah karyawan melayani pelanggan saat memesan menu makanan dan minuman serta menyimpan data-data pesanan ke dalam laporan.

\section{E. Penelitian Terdahulu}

Beberapa hasil penelitian sebelumnya berkaitan dengan sistem informasi pemesanan makanan berbasis android yang digunakan adalah sebagai implementasi untuk menunjang penelitian yang dilakukan. Penelitian [8] mengutarakan Aplikasi pemesanan makanan ini bisa membantu proses servis maupun rekap data untuk report transaksi, dan bisa membuat salah satu penyelesaian untuk mempermudah proses kerja khususnya dalam pemrosesan pesanan menu dan report transaksi.

Penelitian yang dilakukan oleh [9] memakai proses RAD (Rapid Application Development) sistem yang terintegrasi.

\section{METODOLOGI PENELITIAN}

Metode Penelitian pada pokoknya untuk membuktikan fakta dan penyelesaian problem atas penelitian yang dilakukan, dengan pencapaian tujuan digunakan cara yang sesuai dan signifikan demi target yang diteliti. Meniru Sugiyono [2014:2] metode penelitian adalah yang didefinisikan sebagaimana kaidah ilmiah agar memperoleh bukti dengan maksud dan tujuan tertentu.

Agar penelitian ini lebih terkonsep dan terencana sesuai tujuan yang hendak dicapai, sehingga dihasilkan sistem yang teruji serta bisa memecahkan masalah yang diteliti, kerangka kerja yang peneliti lakukan bisa terlihat pada gambar 2 .

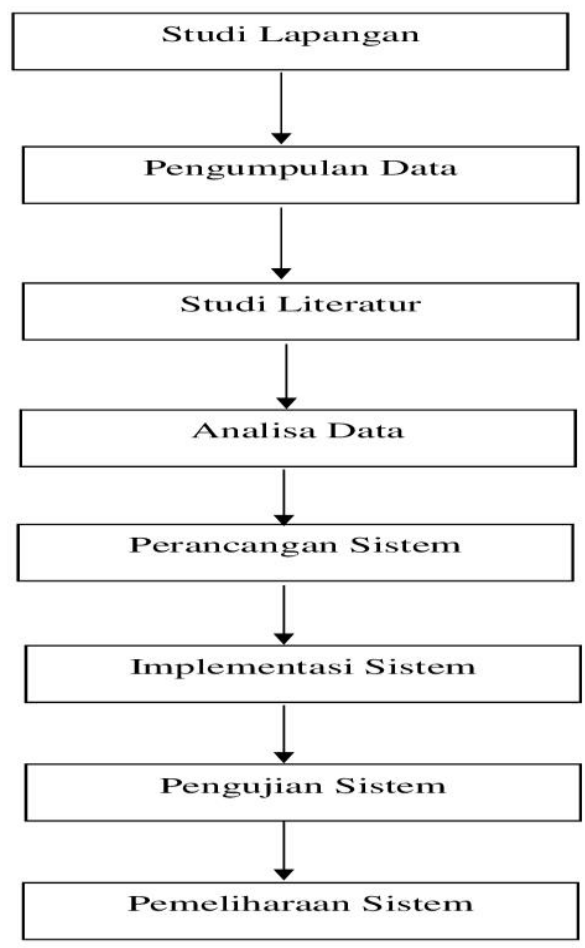

Gambar 2. Kerangka Kerja 
Berikut tahapan metodologi penelitian tersebut adalah :

1. Studi Lapangan

Pengumpulan kebutuhan secara khusus yang diperlukan dalam pembuatan aplikasi. Peneliti menggabungkan data-data yang relevan dari objek penelitian dari pelayan restoran serta mengidentifikasi masalah yang ada didalamnya.

2. Teknik Mengumpulkan Data

a. Observasi

Melakukan pengkajian secara langsung ke lapangan serta meninjau langsung bagaimana penerapan sistem pemesanan makanan dan minuman yang berjalan pada Warciban Cilegon. Untuk mendapatkan data yang dibutuhkan peneliti mengamati semua kegiatan yang berhubungan dengan proses pemesanan, pembayaran sampai pada proses pelaporan.

b. Wawancara

Salah satu cara dalam teknik dokumentasi data yakni dengan dilakukan dialog secara tidak sistematis dengan narasumber yakni owner warciban, karyawan serta orangorang yang terkait dengan proses pemesanan. Wawancara digunakan untuk mengumpulkan dan mendapatkan informasi mendalam yang berhubungan dengan perusahaan yang tidak mungkin diperoleh dari data observasi.

3. Studi Literatur

Suatu cara mengumpulkan data yang ditemukan dari buku referensi, publikasi ilmiah yang berkaitan dengan sistem pesanan makanan dan minuman berbasis android dan metode pengembangan sistem RAD. Teori-teori mengenai kedua hal tersebut, dikaji secara mendalam dan diimplementasikan ke tahapan penelitian selanjutnya.

4. Analisa Data

Suatu kegiatan yang merubah hasil penelitian menjadi informasi yang dipakai untuk mengambil kesimpulan dalam suatu penelitian.

5. Metode Pengembangan dan Perancangan Sistem

Metodologi yang digunakan dalam membuat aplikasi ini yakni Rapid Application Development (RAD) merupakan teknik prosedur pengembangan software yang termasuk dalam teknik bersusun. RAD memprioritaskan pada daur pengembangan secara ringkas, dan tepat. Adapun tahapan di dalam metode pengembangan RAD adalah Requirement planning, Design system, Construction dan testing atau Desain sistem dan spesifikasi desain serta melakukan pengujian sistem kemudian Implementasi sistem. Dalam pelaksanaannya, pengembangan sistem dilakukan sesuai persetujuan pengguna terhadap rancangan yang dihasilkan. Tahap perancangannya, sistem dirancang dinamis agar dapat disesuaikan dengan kebutuhan restoran lainnya yang menggunakan model sistem yang sama.

6. Implementasi Sistem

Tahapan berikutnya sistem di implementasi sistem di restoran Warciban dan akan selalu dievaluasi terhadap efek dari implementasi sistem tersebut.

7. Testing (Pengujian)

Metode pengujian dilakukan 2 tahap pengujian, yaitu usability testing dengan metode kuesioner dan blackbox testing. Hasil pengujian diharapkan adalah 80-100\% dengan kualifikasi sangat baik. Kedua pengujian tersebut melibatkan pengguna menggunakan

8. Pemeliharaan Sistem

Pemeliharan aplikasi yang telah dikerjakan sangat penting sebagai literatur di kemudian hari. Pemeliharaan adalah tahapan akhir dalam pembentukan permulaan fase yang baru yaitu penggunaan.

\section{A. Perancangan Sistem}

\section{HASIL DAN PEMBAHASAN}

Tahap penelitian ini, sistem informasi yang dirancang yakni aplikasi android yang berguna untuk melakukan suatu fungsi penggunaan teknik proses data aplikasi dengan bertujuan mengadakan open platform bagi pengembang teknologi informasi [17]. Berikut merupakan rancangan sistem aplikasi pesanan makanan dan minuman berbasis android.

\section{Flow-map Usulan Secara Komputerisasi}

Flowmap usulan adalah deskripsi proses yang menggambarkan tahap kerja dan runtunannya dengan tanda panah sebagai penghubungnya serta menggambarkan arus dokumen. Flowmap dilakukan untuk mempermudah sistem pemesanan makanan dan minuman di Warciban. Berikut flowmap yang diusulkan :

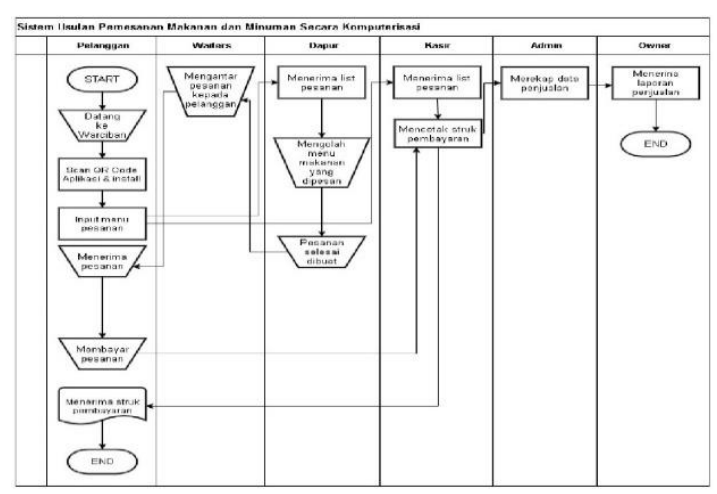

Gambar 3. Flowmap yang Diusulkan 


\section{Diagram Konteks Yang Diusulkan}

Menggambarkan bagaimana sistem informasi yang dibangun berinteraksi dengan external entitas dan sebagai instrumen struktur analisa sistem secara global. Diagram konteks aplikasi pemesanan makanan dan minuman seperti Gambar 4.

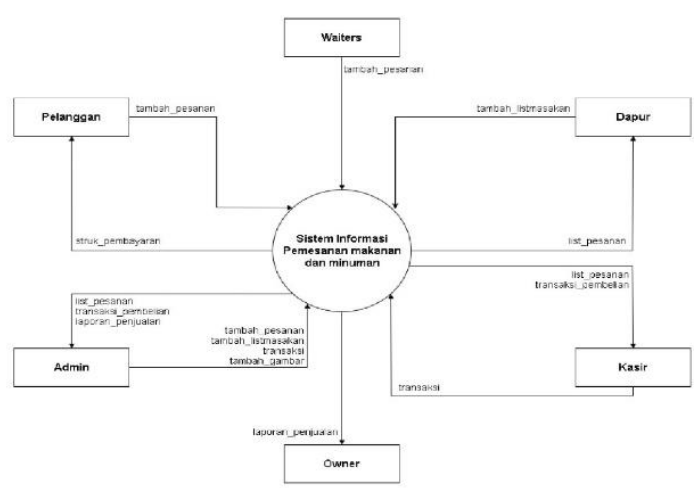

Gambar 4. Diagram Konteks

DFD menggambarkan bentuk diagram konteks yakni berisi dari satu proses, sejumlah entitas luar dan data flow. Diagram konteks mengilustrasikan keutuhan prosedur mengalirnya data dari aplikasi pemesanan makanan dan minuman.

\section{ERD (Entity Relationship Diagram)}

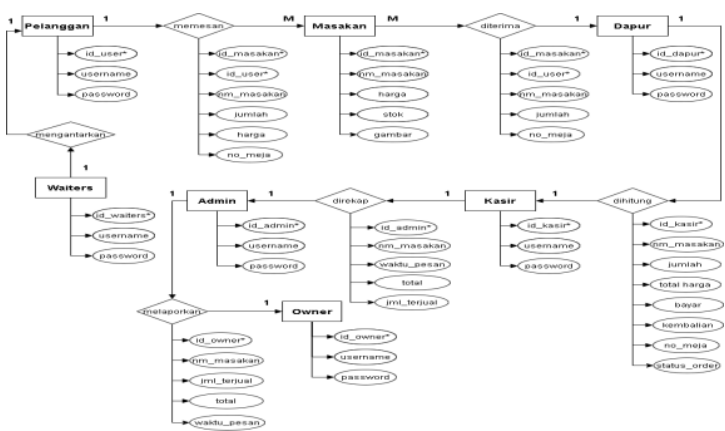

Gambar 5. Entity Relationship Diagram

\section{B. Implementasi Sistem}

\section{Tampilan Pada Website}

1. Halaman Login

Berperan untuk menginput username dan password sebelum akses sistem pemesanan dan bisa masuk ke laman utama user yang terekam. Berikut bentuk halaman login :

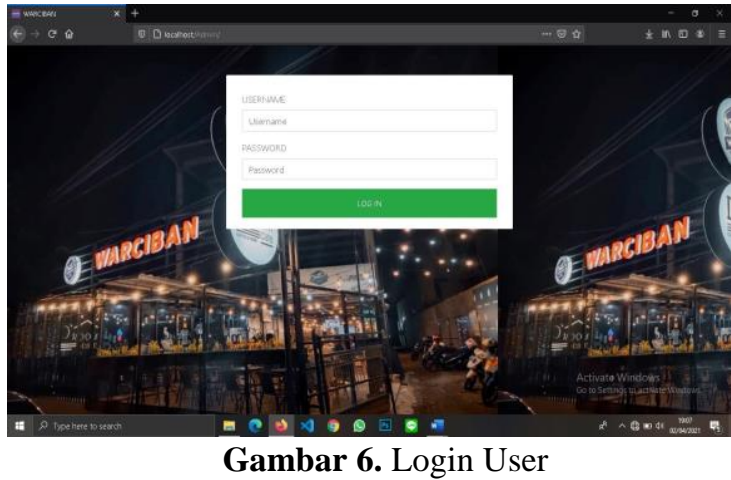

2. Halaman Utama Admin

Tampilan laman admin pada aplikasi berperan untuk memperlihatkan menu utama yang digunakan admin berbentuk opsi menu yang bisa dikerjakan oleh administrator. Berikut tampilan laman utama :

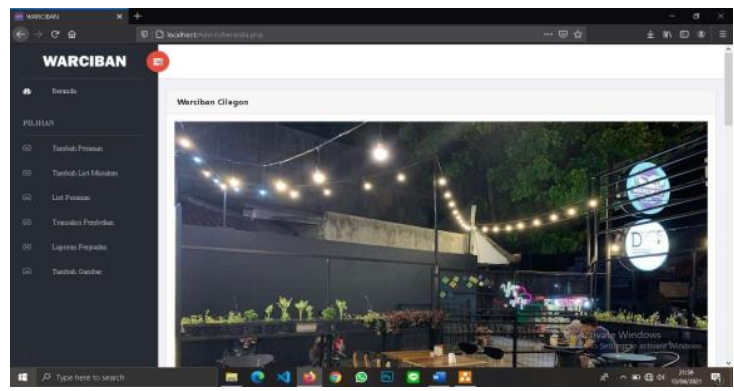

Gambar 7. Halaman Admin

3. Halaman Transaksi Pembelian

Laman transaksi pembelian berfungsi untuk menampilkan informasi transaksi pembelian konsumen. Laman transaksi pembelian sebagai berikut :

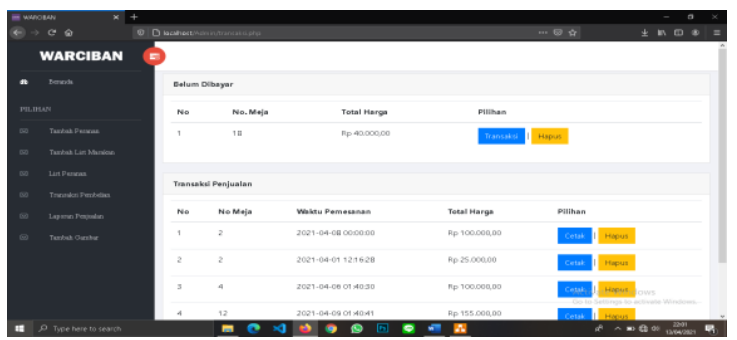

Gambar 8. Transaksi Pembelian

4. Halaman Transaksi Pembayaran

Halaman transaksi pembayaran berfungsi untuk menampilkan informasi transaksi pembayaran konsumen. Adapun bentuk laman transaksi pembayaran sebagai berikut : 


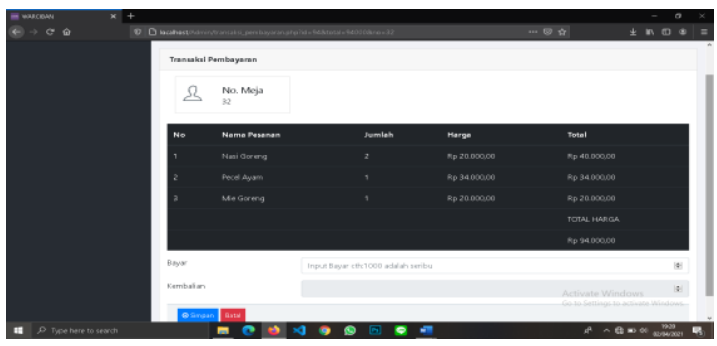

Gambar 9. Transaksi Pembayaran

5. Halaman Laporan Penjualan

Difungsikan untuk menampilkan report penjualan. Adapun tampilan laman laporan penjualan sebagai berikut :

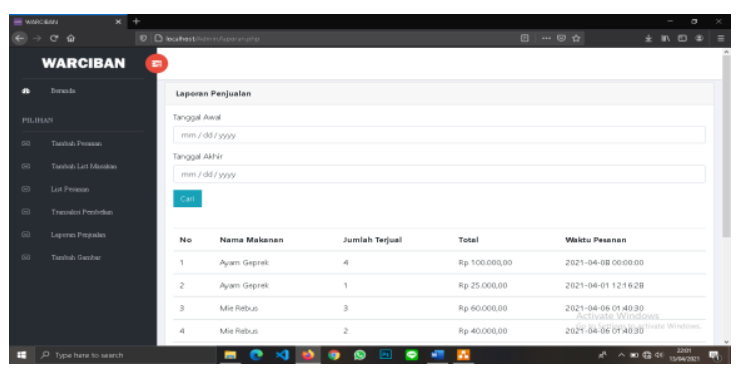

Gambar 10. Laporan Penjualan

\section{Tampilan Pada Android}

\section{List Menu Makanan}

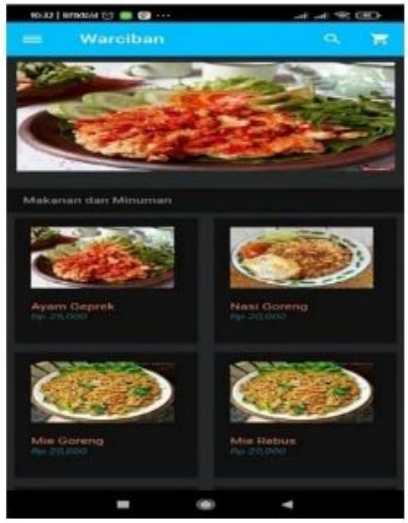

2. Keranjang Pesanan

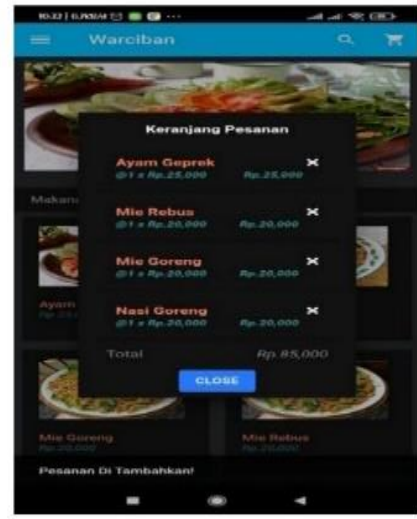

Gambar 11. Menu dan Keranjang Pesanan

Tampilan menu makanan gambar 11 menampilkan halaman berisi detail informasi makanan yang dapat dipesan dan tampilan keranjang pesanan menampilkan halaman detail pesanan, terdapat menu untuk menambah makanan.

\section{QR Code Aplikasi}

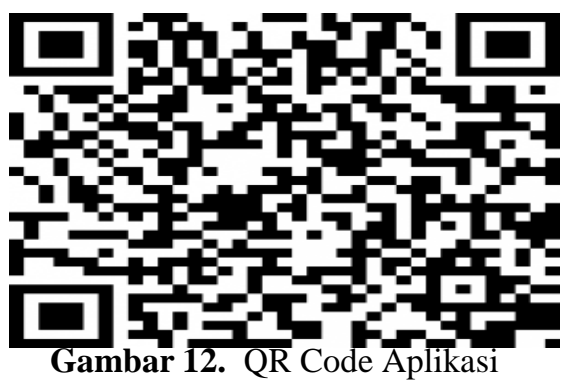

\section{IV.KESIMPULAN}

Berdasarkan hasil kegiatan penelitian yang dilakukan dapat diambil kesimpulan sebagai berikut :

1. Dengan dibuatkannya sistem informasi secara real time memudahkan diantara pihak pemesan dan admin.

2. Sistem ini memiliki jenis pelayanan pesanan makanan dan minuman yang telah tersedia melalui smartphone yang digunakan.

3. Keadaan ini akan mengefektifitaskan waktu bekerja menjadi singkat dan efisien, dan juga dapat dihasilkan informasi yang cepat dan akurat karena memakai database MySQL, sehingga data dapat terintegrasi satu sama lainnya..

\section{REFERENSI}

R. Agustina, D. Suprianto, and I. Muslimin, "Analisis Perancangan Pemesanan Makanan Menggunakan Smartphone Berbasis Android," Smatika J., vol. 7, no. 02, pp. 26-30, 2017, doi: 10.32664/smatika.v7i02.154.

[2] S. Royal, A. Royal, M. Siddik, and A. Nasution, "Teknologi Push Notifikasi Berbasis Android Untuk Informasi Perkuliahan ( Studi Kasus: STMIK Royal Kisaran ) Perencanaan," vol. 9986, no. September, 2018.

[3] R. Setiawan and W. Nugroho, "Rancang Bangun Aplikasi Pemesanan Makanan Berbasis Android," J. Inf. Syst. Informatics, vol. 3, no. 2, pp. 329-340, 2021, doi: 10.33557/journalisi.v3i2.132.

[4] P. Studi, S. Informasi, and U. Trilogi, "Berbasis Android ( Studi kasus: RW 03 Kampung Makasar Jakarta Timur ) Cholis Fajar Putra Reza," vol. 3, no. 1, pp. 1-8, 2021.

[5] W. W. Widiyanto, "Analisa Metodologi Pengembangan Sistem Dengan Perbandingan Model Perangkat Lunak Sistem Informasi Kepegawaian Menggunakan Waterfall Development Model, Model Prototype, Dan Model Rapid Application Development (Rad)," J. Inf. Politek. Indonusa Surakarta ISSN, vol. 4, 
no. 1, pp. 34-40, 2018, [Online]. Available: http://www.informa.poltekindonusa.ac.id/in dex.php/informa/article/view/34.

[6] H. Wijoyo, "Sistem Informasi Pemesanan Makanan Dan Minuman Di Rumah Makan Putri Minang Jaya," JS (Jurnal Sekolah) Univ. Negeri Medan, vol. 3, no. 3, pp. 214224, 2019, doi: http://dx.doi.org/10.24114/js.v3i3.14761.

[7] S. Kosasi and I. D. A. Eka Yuliani, "Penerapan Rapid Application Development Pada Sistem Penjualan Sepeda Online," Simetris J. Tek. Mesin, Elektro dan Ilmu Komput., vol. 6, no. 1, p. 27, 2015, doi: 10.24176/simet.v6i1.234.

[8] R. Suarantalla, F. A. Nugroho, and K. Hermanto, "Rancang Bangun Aplikasi Pemesanan Makanan Berbasis Android Pada Rumah Makan 'Bengawan Tepi Sawah ," Hexagon, vol. 1, no. 2, pp. 4251, 2020.

[9] R. Rosmitalia, "Sistem Pemesanan Makanan Di Rumah Makan Palapa Indah Berbasis Web Service Menggunakan Mobile Android," UIN Raden Fatah Palembang, pp. 1-77, 2016, [Online]. Available:

http://eprints.radenfatah.ac.id/1325/.

[10] J. R. Sagala, "Model Rapid Application Development (Rad) Dalam Pengembangan Sistem Informasi Penjadwalan Belajar Mengajar," J. Mantik Penusa, vol. 2, no. 1, pp. 87-90, 2018.

[11]E. Indra, A. L. Sitanggang, and M. H. Loi, "Rancang Bangun Aplikasi Sistem Ujian Saringan Masuk Sma Berbasis Android (Studi Kasus SMA Amir Hamzah Medan)," J. Sist. Inf. dan Ilmu Komput. Prima(JUSIKOM PRIMA), vol. 2, no. 2, pp. 8-16, 2019, doi: 10.34012/jusikom.v2i2.439.

[12]U. Meningkatkan, H. Belajar, and D. A. N. Kemampuan, "Pembelajaran Sains Dengan Pendekatan Keterampilan Proses Untuk Meningkatkan Hasil Belajar Dan Kemampuan Berpikir Kreatif Siswa," J. Pendidik. Fis. Indones., vol. 7, no. 2, pp. 106-110, 2012, doi: 10.15294/jpfi.v7i2.1081.

[13]A. Adi, "Pemanfaatan Web Service Sebagai Integrasi Data Farmasi di RSU Banyumas ( Web Service Useness as a Pharmacy Data Integration in RSU Banyumas )," J. Juita, vol. II, pp. 231-238, 2013.

[14] S. Purnama, "Al Hikmah Proceedings on Islamic Early Childhood Education: Pengasuhan Digital untuk Anak Generasi Alpha Pengasuhan Digital untuk Anak
Generasi Alpha," Al Hikmah Proc. Islam. Early Child. Educ., vol. 1, pp. 439-502, 2018, [Online]. Available: https://www.academia.edu/download/5736 5843/Pengasuhan_Digital_48_Sigit_Purna ma_493-

502.pdf\%0Ahttp://conference.staialhikmaht uban.ac.id/index.php/ah-piece.

[15] L. M. Cortina, M. Sandy Hershcovis, and K. B. H. Clancy, "The Embodiment of Insult: A Theory of Biobehavioral Response to Workplace Incivility," $J$. Manage., vol. XX, no. X, pp. 1-26, 2021, doi: $10.1177 / 0149206321989798$.

[16] Mustakim, Rosdina, D. Ramadhani, M. Afdal, and M. Rahmawita, "The Classification Status of River Water Quality in Riau Province Using Modified K-Nearest Neighbor Algorithm with STORET Modeling and Water Pollution Index," J. Phys. Conf. Ser., vol. 1783, no. $1, \quad 2021, \quad$ doi: $10.1088 / 1742-$ 6596/1783/1/012020.

[17] N. Safaat, "Rancang Bangun Aplikasi Pembelajaran Berbasis Teknologi Augmented Reality Pada Smartphone Android ( Studi Kasus : Materi Sistem Tata Surya Kelas Ix ) Nazruddin Safaat H Teknik Informatika UIN SUSKA Riau diatas layer dunia nyata secara real-time seolah-ola," J. Sains, Teknol. dan Ind., vol. 12, no. 1, pp. 41-47, 2014. 